\title{
Akademi Lalare Orchestra Sebagai Pengembang Kreativitas Musik Pada Anak Usia Dini di Kabupaten Banyuwangi
}

\author{
Gandhes Sembodro Budy ${ }^{1}$, Setya Yuwana ${ }^{2}$, Setyo Yanuartuti ${ }^{3}$ \\ ${ }^{1}$ Program Studi S2 Pendidikan Seni Budaya, Universitas Negeri Surabaya, Surabaya, Indonesia \\ ${ }^{2}$ Universitas Negeri Surabaya, Surabaya, Indonesia \\ Email: ${ }^{1}$ gandhes.18006@mhs.unesa.ac.id, ${ }^{2}$ yuwana_unesa@yahoo.com, \\ ${ }^{3}$ setyoyanuartuti@unesa.ac.id
}

\begin{abstract}
Creativity is a talent possessed by every individual and can be honed or nurtured through the right educational institutions. In the formation of creativity in early childhood, children need help to build their creativity. Supporting factors and the formation of a child's creativity, namely with the full support of the people or the environment around them. With the education of one's creativity to grow and develop, the Lalare Orchestra Academy is an educational institution that teaches students to be more creative in playing musical instruments. This study aims to determine the process of developing creativity carried out at the Lalare Orchestra Academy and to examine the creativity results obtained by students after studying at this Institute. This research uses a qualitative descriptive method. The results showed that the development of creativity carried out at the Lalare Orchestra Academy was a learning process carried out by learning to play traditional Banyuwangi musical instruments using improvisation performed by children. The results obtained by the students were that students were able to improvise on existing songs and were able to play music very well, while the results of their creativity were that students were able to create according to their imagination through the music they played with available musical instruments.
\end{abstract}

Keywords: Lalare Orchestra Academy Institute, creativity, early childhood education

\begin{abstract}
Abstrak: Kreativitas merupakan bakat yang dimiliki oleh setiap individu serta dapat diasah atau dipupuk melalui lembaga pendidikan yang tepat. Di dalam suatu pembentukan kreativitas pada anak usia dini anak-anak memerlukan bantuan untuk membangun kreativitasnya. Faktor-faktor penunjang serta terbentuknya suatu kreativitas pada anak yaitu dengan dukungan penuh dari orang-orang atau lingkungan di sekelilingnya. Dengan adanya pendidikan, kreativitas seseorang dapat tumbuh dan berkembang. Lembaga Akademi Lalare Orchestra merupakan sebuah lembaga pendidikan yang mengajarkan peserta didik untuk lebih kreatif dalam memainkan alat musik. Penelitian ini bertujuan untuk mengetahui proses pengembangan kreativitas yang dilakukan di Lembaga Akademi Lalare Orchestra serta mengkaji hasil kreativitas yang didapatkan siswa setelah belajar di lembaga ini. Penelitian ini menggunakan metode deskriptif kualitatif. Hasil penelitian menunjukkan bahwa pengembangan kreativitas yang dilakukan di Lembaga Akademi Lalare Orchestra merupakan proses belajar yang dilakukan dengan belajar memainkan alat musik tradisional Banyuwangi dengan menggunakan improvisasi yang dilakukan oleh anak-anak. Hasil yang diperoleh oleh siswa yaitu siswa mampu melakukan improvisasi pada lagu yang sudah ada dan mampu memainkan musik dengan sangat baik sedangkan hasil pencapaian kreativitasnya sendiri yaitu siswa mampu berkreasi sesuai dengan imajinasi mereka melalui musik yang mereka mainkan dengan alat musik yang sudah tersedia.
\end{abstract}

Kata Kunci: Lembaga Akademi Lalare Orchestra, kreativitas, anak usia dini

\author{
Article info: \\ Received: 18 Maret 2021 \\ Reviewed:23 April 2021 \\ Accepted:26 Juni 2021
}


Gandhes Sembodro Budy ${ }^{1}$, Setya Yuwana ${ }^{2}$, Setyo Yanuartuti ${ }^{3}$

Akademi Lalare Orchestra Sebagai Pengembang Kreativitas Musik Pada Anak Usia Dini

di Kabupaten Banyuwangi

\section{PENDAHULUAN}

Banyuwangi merupakan suatu Kabupaten paling timur di pulau Jawa yang memiliki bentang alam yang luas, antara lain dataran tinggi yang berupa daerah pegunungan serta dataran rendah seperti pantai yang mengelilinginya. Tidak hanya itu, Banyuwangi juga memiliki berbagai macam kesenian daerah yang menjadi aset utama yang dapat dikembangkan dalam pariwisata, seni, dan budaya (D.E, 2017; Wessing, 2019; Yashi, Seblang, Using, \& Timur, n.d.). Keberagaman yang dimiliki daerah ini yang menjadikan Banyuwangi sangat kaya akan potensi sumber daya manusia serta sumber daya alam. Potensi besar yang dimiliki oleh Banyuwangi berkelindan pada potensi pariwisata yang ikut melejit pada saat ini. Pariwisata di Banyuwangi sudah tidak asing lagi di telinga masyarakat dalam negeri maupun masyarakat luar negeri. Dengan adanya potensi pariwisata tersebut, Banyuwangi mulai melakukan promosi baik secara domestik maupun internasional. Pariwisata yang semakin melejit ini menjadikan pemerintah daerah ingin lebih melestarikan kebudayaan leluhur serta mengusung pendidikan kesenian kepada anak-anak generasi muda, agar mereka mampu menghargai serta melestarikan warisan budaya dan mampu mengembangkan kesenian daerah Banyuwangi. Pengelolaan warisan budaya merupakan salah satu isu penting dalam suatu wacana pembangunan kebudayaan Indonesia (Facca \& Aldrich, 2011; Francis-Lindsay, 2009), pertemuan politik kebudayaan merupakan perwujudan atas dasar-dasar suatu kebudayaan baru yang mencakup kesenian, kesusastraan, kesusilaan dan warisan budaya merupakan latar belakang masyarakat yang tidak bisa diabaikan (Bryan-Wilson, 2017; Warren, 2012).

Oleh karena itu, sangat diperlukan penggerak, pemerhati dan pendukung dari berbagai lapisan masyarakat. Dengan demikian, perlu ditumbuh-kembangkan motivasi yang kuat untuk ikut tergerak berpartisipasi melaksanakan pelestarian, yaitu antara lain untuk memotivasi serta menjaga dan mempertahankan warisan budaya yang diwarisi oleh para leluhur sebelumnya. Pelestarian suatu kesenian dapat dilihat dari adanya suatu dokumentasi yang merupakan bukti konkret adanya suatu kesenian terdahulu (Barthel, 1989). Seni merupakan suatu identitas lokal sebuah daerah dan merupakan suatu penunjang perkembangan masyarakat dari berbagai bidang, salah satu identitas yang dapat menunjukkan bagaimana daerah tersebut akan dipandang oleh daerah lainnya, suatu kesenian membutuhkan promosi dan pemasaran agar tetap terjaga kelestariannya salah satunya dengan dokumentasi, dokumentasi sangat berperan penting sebagai wadah pelestarian kesenian untuk memegang peranan penting tersebut (Silk, Gildenhard, \& Barrow, 2014; Wilcox, 2016).

Kabupaten Banyuwangi merupakan salah satu daerah yang mempunyai kesenian yang berbeda dan menjadikan Banyuwangi memiliki ciri khas dalam keseniannya. Saat ini di Kabupaten Banyuwangi telah berkembang suatu lembaga pendidikan non-formal untuk menyalurkan bakat seni anak-anak terutama anak-anak usia dini yang masih duduk di jenjang sekolah dasar sampai sekolah menengah pertama. Lembaga pendidikan nonformal ini bernama Akademi Lalare Orchestra. Akademi Lalare Orchestra sebagai lembaga pendidikan non-formal merupakan lembaga pendidikan yang terjadi pada suatu kelompok masyarakat (Koops, 2017). Di dalam suatu pendidikan non-formal yang merupakan bagian pendidikan yang dilakukan oleh masyarakat dibutuhkan suatu teknologi pendidikan sebagai suatu disiplin ilmu yang mempunyai kontribusi dalam pemecahan suatu masalah belajar pada pendidikan formal ataupun non-formal, serta teknologi pendidikan ini dapat diaplikasikan juga pada pendidikan non-formal (Partti \& Karlsen, 2010; Vasil, Weiss, \& Powell, 2019).

Lembaga Akademi Lalare Orchestra merupakan kumpulan anak-anak usia dini yang tertarik atau bahkan sudah mahir memainkan alat musik tradisional Banyuwangi. Akademi Lalare Orchestra ini mengajarkan para peserta didiknya untuk mahir dalam bermain musik tradisional namun dalam pengemasan pembelajarannya dikemas dalam secara modern. Hal ini memberikan kesan hybrid, di mana memadukan musik tradisional yang disampaikan secara modern dengan pendekatan pembelajaran modern (Bhabha, 1994; Jorgensen, 2010). Pembelajaran hybrid tersebut memberikan bantuan dan bimbingan orang dewasa dan sekelilingnya untuk menumbuhkan kreativitas mereka dalam hal bermusik (Bhabha, 1994; Ghaem Sigarchian et al., 2018; Tollefson, 1999). Oleh karenanya, anak-anak akan mengetahui bakat serta minat mereka, 
anak-anak juga dapat menyalurkan serta bakat mereka akan lebih terasah dan terarah dalam bermusik, karena adanya bimbingan langsung dari para ahli atau guru musik yang sudah profesional dalam bidangnya dan sudah tidak diragukan lagi kemampuannya.

Transformasi yang terjadi di dalam dunia pendidikan saat ini, khususnya seni musik mempunyai pengaruh besar yang dapat menyatukan berbagai profesi seperti mahasiswa, pendidik, maupun seniman musik untuk berbaur ke dalam musik orkestra simfoni (Kladder, 2020; Lin, 2019; Miksza, 2013; Vasil et al., 2019). Dengan banyaknya dukungan dari kalangan masyarakat membuat musik orkestra simfoni ini menggapai suatu pertunjukan yang estetis, akhirnya dengan begitu terbentuklah sebuah kelas yang bertujuan sebagai identitas kolektif yang dibentuk melalui kode-kode sosial seperti atribut, kesetiaan, serta afiliasi yang menentukannya (Stevens, 2018). Munculnya kelas musik orkes simfoni yang sudah ada sejak tahun 1960-an hingga saat ini merupakan hasil dari proses panjang hubungan antara kebudayaan musik dan pemerintah (Hart, Chartier, Kenyon, \& Long, 2018; Stevens, 2018). Dengan adanya perkembangan jaman seperti saat ini membuat musik orkestra simfoni tidak hanya sebagai musik budaya barat saja, namun sudah menjadi musik universal dan menjadi aset antar bangsa.

Universalitas musik orkestra simfoni menjadi daya tarik terhadap masyarakat untuk mempelajarinya. Oleh karenanya sebutan orchestra di dalam Akademi Lalare Orchestra merupakan hanya sebuah nama untuk menarik masyarakat khususnya generasi milenial agar tertarik dengan musik barat meskipun sebenarnya Akademi Lalare Orchestra merupakan sebuah lembaga kesenian yang mengajarkan tentang musik tradisional. Hal ini menjadi menarik untuk dibahas, terutama tentang latar belakang Akademi Lalare Orchestra sebagai lembaga pendidikan nonformal yang mengakomodasi kebutuhan pelestarian musik tradisi Banyuwangi yang tetap mempertimbangkan kreativitas di dalamnya; dan pada akhirnya dapat mendeskripsikan proses pengembangan kreativitas musik pada anak usia dini.

\section{METODE}

Desain penelitian ini menggunakan prinsip penelitian kualitatif yang memanfaatkan data berbasis kata-kata deskriptif sebagai model utama baik dalam penulisan maupun analisis
(Denzin \& Lincoln, 2018; Holladay \& Powell, 2018; Lune \& Berg, 2017), terhadap kreativitas musik anak usia dini di Akademi Lalare Orchestra. Di dalam proses penelitian kualitatif ini melibatkan beberapa upaya penting seperti mengumpulkan data yang spesifik dari partisipan, mengajukan pertanyaan ataupun prosedur, menganalisis data secara induktif serta menafsirkan makna data (Lune \& Berg, 2017).

Sumber data dalam penelitian ini adalah Akademi Lalare Orchestra yang berlokasi di Kampus KLLC Jl. KH Agus Salim No 31A Banyuwangi. Objek dalam penelitian ini adalah proses pembelajaran musik di Akademi Lalare Orchestra sebagai identifikasi atas data yang digunakan untuk memecahkan permasalahan kreativitas. Data diperoleh dari observasi, wawancara, dan studi dokumentasi atas Akademi Lalare Orchestra dan pembelajarannya terutama yang berkaitan dengan Akademi Lalare Orchestra sebagai Pengembang Kreativitas Musik pada Anak Usia Dini di Kabupaten Banyuwangi. Data yang diperoleh kemudian dianalisis dengan moda interaktif yang dimulai dengan penjabaran tentang profil Akademi Lalare Orchestra yang menjelaskan latar belakangnya sebagai akademi musik pengembang kreativitas anak usia dini di Banyuwangi (Miles, Huberman, \& Saldana, 2018). Selanjutnya, latar belakang tersebut diwacanakan dengan pembelajaran yang dilakukan oleh Akademi Lalare Orchestra.

\section{HASIL DAN PEMBAHASAN Profil Lembaga Akademi Lalare Orchestra}

Pendidikan anak usia dini merupakan suatu pendidikan yang akan mengembangkan pikiran serta kreativitas anak, karena pendidikan anak usia dini merupakan gerbang awal suatu pendidikan untuk melanjutkan pendidikan di jenjang selanjutnya. Pendidikan yang dilakukan sejak dini merupakan suatu investasi besar untuk masa yang akan datang. Pendidikan anak usia dini merupakan pendidikan yang memerlukan pembinaan serta bimbingan untuk memberikan rangsangan agar dapat membantu tumbuh kembang pada anak. Hal ini juga diungkapkan oleh Mawson (2010) bahwa pendidikan usia dini merupakan pendidikan yang mampu merangsang perkembangan otak pada anak. Dari hasil-hasil studi dibidang neurologi mengungkapkan bahwa ukuran otak anak pada usia 2 tahun telah mencapai $75 \%$ dari ukuran otak ketika dewasa, 
dan pada umur 5 tahun telah mencapai $75 \%$ (Csikszentmihalyi, 2014; Sampurno, 2015), artinya bahwa pada usia dinilah bahwa sejak dalam kandungan pun telah terjadi perkembangan otak kecerdasaan bahkan kemampuan belajar anak yang signifikan. Menurut Sistem Pendidikan Nasional yang sudah diatur pada Undang-undang Nomor 20 Tahun 2003 Bab VI pasal 13 ayat (1) bahwa pendidikan digolongkan menjadi tiga bagian, yaitu pendidikan formal, pendidikan non-formal dan pendidikan informal. Pendidikan formal merupakan pendidikan yang dilakukan secara sistematis, teratur, berstruktur, berjenjang, serta bertingkat, yang dimulai dari taman kanakkanak hingga jenjang perguruan tinggi, untuk pendidikan non-formal sendiri merupakan pendidikan yang dilakukan di luar sekolah namun sudah terorganisasi; dan untuk pendidikan informal merupakan pendidikan utama yang didapatkan oleh anak yaitu pendidikan yang terdapat pada keluarga masing-masing individu. Akademi Lalare Orchestra merupakan lembaga pendidikan nonformal yang didirikan oleh Bapak Hasan Basri pada tanggal 28 Oktober 2018. Lembaga ini tergolong lembaga pendidikan non-formal yang masih baru didirikan di Banyuwangi. Pendidikan non-formal merupakan pendidikan yang berkembang dan tumbuh dalam suatu masyarakat. Di dalam suatu pendidikan nonformal yang merupakan bagian pendidikan yang dilakukan oleh masyarakat dibutuhkan suatu teknologi pendidikan sebagai suatu disiplin ilmu yang mempunyai kontribusi dalam pemecahan suatu masalah belajar pada pendidikan formal ataupun non-formal, serta teknologi pendidikan ini dapat diaplikasikan juga pada pendidikan non-formal (Partti \& Karlsen, 2010).

Akademi Lalare Orchestra sangat unik untuk dibahas, mulai dari anggotanya yang didominasi oleh anak-anak usia dini yaitu anakanak sekolah dari kelas 4 SD sampai SMP. Dalam Akademi Lalare Orchestra ini diajarkan beberapa teknik serta cara bermain musik dengan baik dan benar. Untuk saat ini siswa yang tergabung di dalam Akademi lalare Orchestra sudah mencapai 130 siswa dan sudah berlangsung dua angkatan. Untuk pengelompokan kelas dikelompokkan menurut jenis alat musiknya, bukan berdasarkan usianya. Kegiatan kreativitas yang dilakukan di dalam Lembaga Akademi Lalare Orchestra ini yaitu melatih para siswa agar mampu memainkan musik sesuai dengan bakat dan minat anak, serta siswa mampu menciptakan sebuah karya baru dan mengaransemen lagu yang sudah ada. Kreativitas merupakan salah satu aktivitas dalam menghasilkan sesuatu yang baru atau berbeda (Glăveanu, 2016; James \& Sternberg, 2010). Seni, ilmu pengetahuan, dan filsafat adalah sama-sama kegiatan kreatif, yaitu kegiatan dalam menemukan sesuatu yang berbeda dari yang sebelumnya. Kegiatan kreativitas juga sangat erat kaitannya dengan pendidikan, seperti pendidikan seni. Dengan banyaknya peserta didik setiap tahunnya akhirnya lembaga ini sudah menyiapkan kelaskelas yang nyaman untuk belajar bermusik dan sudah diklasifikasikan menurut alat musik yang sudah ada seperti kelas biola, saron, angklung, dan vokal. Dalam hal ini, siswa sebanyak 130 orang yang terbagi menjadi dua angkatan, dan terdiri dari beberapa kelas yaitu untuk angkatan yang pertama, kelas biola sebanyak 6 siswa, kelas angklung 10 siswa, kelas vokal 14 siswa, kelas kendhang 19 siswa, dan kelas saron 42 siswa. Sedangkan untuk angkatan yang kedua tetap dengan pembagian kelas yang sama hanya saja jumlah yang berbeda yaitu pada kelas biola 5 siswa, kelas angklung 2 siswa, kelas vokal 17 siswa, kelas kendhang 9 siswa dan kelas saron 26 siswa.

Di dalam lembaga ini sangat dibutuhkan kreatifitas dari murid maupun guru untuk menunjang perkembangan lembaga agar menjadikan lembaga ini semakin dikenal oleh masyarakat. Kreativitas merupakan suatu pola pikir yang merangsang individu untuk membuat serta menciptakan hal yang baru. Kreativitas umumnya dimaknai sebagai sebuah kemampuan untuk menciptakan (to create) dan dengan hal tersebut kreativitas dalam konteks yang lebih luas dapat dimaknai sebagai kemampuan untuk merespon ide, masalah, dan berpikir dengan cepat (Black \& Browning, 2011; James \& Sternberg, 2010; Sampurno, 2015; Scott \& Julie-ann, 2019). Hal ini juga diungkapkan oleh Iswantara (2017:7) bahwa kreativitas merupakan hasil dari interaksi antara individu satu dengan individu yang lain pada suatu lingkungan, kemampuan untuk membuat hal baru serta kombinasi baru, berdasarkan informasi, data, atau unsur-unsur yang sudah ada sebelumnya serta pengalaman dan pengetahuan yang sudah diperoleh individu dalam hidupnya di lingkungan masyarakat, 
sekolah, ataupun keluarga. Lembaga Akademi Lalare Orchestra ini merupakan suatu lembaga yang bertujuan untuk membentuk anak-anak kreatif, di mana kreativitas merupakan kemampuan seseorang untuk menghasilkan suatu produk maupun gagasan apa saja yang merupakan sesuatu yang baru dan sebelumnya tidak dikenal pembuatnya (Astuti, 2010:252). Hal tersebut dapat berupa kegiatan yang imajinatif atau sintesis pemikiran yang hasilnya bukan hanya perangkuman, hal tersebut bisa merupakan suatu pola baru maupun gabungan informasi yang sudah diperoleh dari pengalaman sebelumnya dan pencangkokan hubungan lama kedalam situasi baru. Ia harus mempunyai maksud serta tujuan yang ditentukan, ia dapat berupa produk seni, kesusasteraan, produk ilmiah ataupun suatu metodologi. Oleh sebab itu, kreativitas merupakan hal yang baru dan dikembangkan melalui pengalaman atau pengetahuan yang sudah diperoleh oleh seseorang.

Lembaga Akademi Lalare Orchestra merupakan suatu lembaga musik penunjang kreativitas anak. Pada Lembaga ini siswa diajarkan untuk mengembangkan kreativitasnya dalam berkesenian serta menciptakan lagu-lagu baru maupun mengaransemen lagu. Mereka diajarkan selalu aktif dan kreatif untuk mengembangkan musik tradisional Banyuwangi. Sebenarnya tujuan pendidikan seni bukan untuk membina anak-anak menjadi peseni/seniman, melainkan untuk mendidik anak agar menjadi anak yang lebih kreatif. Dengan demikian, dapat dikatakan bahwa pembelajaran seni khususnya yang berkaitan dengan praktik berkesenian dapat digunakan sebagai alat pendidikan.

Kegiatan kreativitas memang sangat diperlukan dalam kehidupan sehari-hari sebagai penunjang kemampuan berpikir setiap individu untuk menjadikan manusia yang lebih menghasilkan karya-karya baru. Di dalam berkesenian khusunya dalam bermusik sangat dibutuhkan kemampuan berpikir kreatif, karena dengan memiliki kreativitas dapat menciptakan karya musik yang baru. Kreativitas dalam hal bermusik merupakan sebuah dasar tumbuhnya suatu karya-karya yang dapat dinikmati oleh penikmat seni serta dapat dimainkan oleh pelaku seni, seperti karya-karya komponis yang sudah terkenal. Kreativitas dalam bermusik merupakan aktivitas serta gaya seseorang dalam bermain musik (Humphreys, 1958; Lin, 2019). Dengan adanya aktivitas dan gaya tersebut membuat seseorang mampu menciptakan serta menghasilkan sebuah karya musik yang kemudian dapat dianalisa, sehingga secara prosesnya kreativitas adalah berupa karya musik dan analisis musik.

Negosiasi improvisasi sebagai implikasi dari pengembangan kreativitas di Akademi Lalare Orchestra

Suatu produk karya musik merupakan hasil kreativitas apabila produk tersebut dapat menghasilkan sesuatu karya baru dan berguna. Kreativitas juga merupakan kemampuan seseorang dalam membuat kombinasi baru berdasarkan data ataupun informasi serta unsurunsur yang sudah ada. Di dalam musik yang dimaksud kreativitas musik adalah seseorang yang dapat menciptakan lagu, instrument ataupun mengaransemen musik baru yang belum pernah diciptakan oleh orang lain sehingga dapat dinikmati oleh penikmat seni (Habsari, 2005:85).

Pengembangan kreativitas musik dapat dilakukan dengan cara improvisasi dan komposisi (Humphreys, 1958; Lin, 2019). Dalam Akademi Lalare Orchestra siswa diajarkan untuk lebih kreatif dalam bermusik yaitu dengan melakukan improvisasi. Para siswa ini dalam masing-masing angkatan diajarkan pendidikan kreativitas dengan langkah awal yaitu improvisasi yang diajarkan melalui cara melihat, meniru dan memperagakan atau mempraktikkan arahan dari guru kepada siswa (Abramo \& Reynolds, 2015).

Improvisasi dapat diartikan sebagai penambahan atau pengembangan dalam sebuah lagu. Pengertian improvisasi dalam musik adalah memainkan alat musik secara spontan tanpa ada perencanaan atau bacaan tertentu (Banoe, 2003), sedangkan improvisasi dalam lagu merupakan kebebasan dalam memainkan sebuah notasi dengan tidak terikat atau tidak sesuai dengan notasi aslinya (Abramo \& Reynolds, 2015). Untuk dapat melakukan sebuah improvisasi, siswa sebagai pemain musik harus memahami serta sudah menghafal notasi lagu serta menguasai lagu tersebut. Di dalam improvisasi juga dibutuhkan latihan yang terus menerus serta pemahaman lagu yang baik, dengan begitu pemusik akan bisa menyalurkan kreativitasnya dalam mengimprovisasi lagu tersebut. Namun di dalam bermusik juga tidak bisa mengimprovisasi bila tidak sesuai takarannya, karena hal tersebut dapat menghilangkan keorisinilan lagu tersebut. 
Gandhes Sembodro Budy ${ }^{1}$, Setya Yuwana ${ }^{2}$, Setyo Yanuartuti ${ }^{3}$

Akademi Lalare Orchestra Sebagai Pengembang Kreativitas Musik Pada Anak Usia Dini

di Kabupaten Banyuwangi

$\begin{array}{ccr}\text { Akademi } & \text { Lalare } & \text { Orchestra } \\ \text { mengimplementasikan } & \text { improvisasi dalam }\end{array}$ pembelajaran oleh para pengajarnya. Para siswa diajarkan untuk berpikir kreatif agar mereka mampu dan dapat mengimprovisasi lagu yang sudah ada dan menjadikan lagu tersebut menjadi lebih berwarna dan baru. Oleh karena itu, siswa dapat berpikir bagaimana cara agar lagu yang mereka mainkan memiliki kesan yang berbeda namun tetap mempertahankan keorisinalan lagu tersebut. Dalam improvisasi pada setiap kelas berbeda-beda dikarenakan alat musik yang dimainkan juga berbeda-beda perkelas. Improvisasi di kelas biola diajarkan melalui pelatihan tangga nada serta teknik memainkan alat musik biola mulai dari memegang dan menggesek serta memainkan sebuah lagu dengan utuh. Untuk dikelas angklung siswa diajarkan teknik-teknik bermain angklung yang benar dengan menggunakan rasa serta siswa diajarkan teori mengenai tangga nada didalam angklung itu sendiri, karena angklung Banyuwangi dan angklung sunda atau angklung yang lain memiliki suara dan tangga nada yang berbeda. Pada kelas vokal, siswa diajarkan cara bernyanyi yang benar menggunakan teknik vokal yang benar juga, mereka diajarkan pula mengenai penghayatan dalam setiap lagu yang mereka bawakan, apalagi bernyanyi dengan iringan musik tradisional Banyuwangi harus mempunyai skil tersendiri dan cengkok yang khas agar lebih merasuk kedalam alunan musik Banyuwangi. Begitu pula pada kelas kendhang, kelas ini diajarkan tentang skil menabuh kendhang yang benar dan teknik memainkan alat musik kendhang, dan yang terakhir adalah kelas saron, kelas ini juga mempunyai sistem pembelajaran yang sama yang dilakukan dalam kelas angklung, karena sama-sama merupakan alat musik yang tergolong kedalam alat musik melodis, improvisasi di dalamnya diajarkan melalui teknik-teknik bermain saron yang benar serta tangga nada pada saron juga diajarkan.

Dengan adanya improvisasi yang dilakukan pada setiap kelas tersebut mulai dari teknik memainkan alat musik sampai teori tentang tangga nada yang terdapat disetiap alat musik mengajarkan anak lebih kreatif dalam hal berkesenian dan memainkan alat musik sehingga terciptalah improvisasi-improvisasi yang dihasilkan anak-anak melalui proses belajar kreatif di dalam setiap kelas. Seperti contohnya hasil improvisasi dimainkan pada lagu Kendhang Kempul yang masih orisinal lalu diimprovisasi kedalam musik yang lebih bernuansa modern.

Dalam Lembaga Akademi Lalare Orchestra selain diajarkan improvisasi juga diajarkan teknik bermain alat musik dan juga teori-teori musik. Lembaga Akademi Lalare Orchestra ini juga bisa disebut sebagai lembaga pendidikan seni. Pendidikan seni sendiri merupakan sesuatu hal atau proses untuk mengolah berbagai keterampilan berpikir. Hal tersebut meliputi keterampilan kreatif, inovatif, dan kritis. Keterampilan ini di olah melalui cara belajar induktif dan deduktif secara seimbang. Dalam proses belajar mengajar menghasilkan sebuah kreativitas, menurut pendapat Supriadi (1994:116) bahwa ilmu sebagai sistem berpikir yang melibatkan serangkaian aktivitas kreatif dan imajinatif dalam upaya mencapai kebenaran. Di dalam pengembangan kreativitas terdapat dua periode yang diungkapkan oleh pendapat Supriadi (1994:121) bahwa ada dua periode kritis yang terdapat dalam perkembangan kreativitas di bidang ilmu, yaitu periode formatif dan periode embrionik. Periode formatif yaitu periode dimana individu melakukan hal kreatif dimulai dari mengembangkan wawasan berpikirnya, memperkaya pengalamannya, serta melatih kepekaan persepsinya terhadap tantangan yang berasal dari lingkungannya. Setelah adanya perkembangan formatif terdapat periode produktif yang dimana karya-karya kreatif seorang individu mulai lahir dan wujudnya konkret, namun antara periode formatif dan produktif ada suatu periode yaitu periode embrionik yang merupakan proses kreatif suatu individu yang sudah menghasikan karya-karya namun mereka belum menemukan formatnya yang utuh dan matang.

Dengan demikian, kreativitas sangat dibutuhkan dalam proses belajar mengajar di dalam suatu lembaga pendidikan. Lembaga Akademi Lalare Orchestra merupakan lembaga pendidikan yang masih tergolong baru berdiri, namun lembaga ini sudah mampu menghasilkan anak-anak generasi muda yang kreatif dalam melestarikan kesenian daerah yaitu dalam bidang seni musik serta lembaga ini sudah mendapatkan beberapa penghargaan dan sudah diakui oleh pemerintahan Banyuwangi sebagai sarana untuk menyalurkan bakat anak-anak daerah dalam hal seni musik. Dengan adanya kreativitas yang dibangun sejak dini, dapat 
meningkatkan pikiran serta mental anak yang sudah bergabung didalam lembaga tersebut. Kreativitas juga dibutuhkan dalam Lembaga Akademi Lalare Orchestra ini, karena dengan adanya kreativitas mampu mendorong siswa serta guru berpikir lebih keras untuk menciptakan karya-karya baru yang lebih fresh dan modern namun tetap dikemas menggunakan alat musik tradisional.

Hasil dari pengembangan kreativitas yang dihasilkan oleh siswa Akademi Lalare Orchestra merupakan suatu ilmu baru yang didapatkan oleh anak-anak yang sebelumnya belum mereka ketahui dan mereka pelajari disekolah formal. Siswa akan lebih mengetahui teknik bermain musik yang benar sesuai dengan kelas yang meraka ambil, dan untuk kelas vokal siswa dapat bernyanyi menggunakan teknik bernyanyi yang benar serta mampu membawakan sebuah lagu yang bisa dinikmati oleh penikmat seni. Dengan adanya proses belajar mengajar di dalam Lembaga Akademi ini membuat siswa mengetahui teori-teori dalam seni musik serta mereka tidak hanya asal-asalan di dalam memainkan alat musik tradisional Banyuwangi. Di lembaga akademi ini siswa diajarkan tata cara memainkan alat musik yang benar serta anak-anak diajarkan sesuai dengan minat dan bakat mereka.

\section{KESIMPULAN}

Dengan adanya pembahasan diatas dapat disimpulkan bahwa Lembaga Akademi Lalare Orchestra merupakan salah satu lembaga pendidikan seni yang mengembangkan kreativitas anak usia dini. Lembaga yang baru saja beridri namun sudah mengahasilkan anakanak kreatif, dengan kekreatifan tersebut dapat menghasilkan sebuah kejuaraan. Pendidikan seni dan kreativitas mempunyai kesinambungan dalam hal pendidikan. Maka dari itu kreativitas sangat dibutuhkan untuk membangun generasi baru agar tidak melakukan imitasi atau pengulangan. Dengan adanya kreativitas yang baru dan masih segar, generasi muda mampu membuat suatu karya baru yang fresh dan kekinian. Lembaga Lalare Orchestra ini merupakan sekolah atau kursus yang mengedepankan skil serta teori, dengan begitu hasil yang didapatkan dari pendidikan kreativitas yang dilakukan di dalam akademi yaitu siswa lebih mampu untuk mengembangkan potensi diri, siswa dapat memainkan musik dengan teknik yang benar serta siswa mengetahui dan mempelajari teori- teori musik yang benar dan menggunakan notasi musik dalam setiap garapannya.

$$
\text { Pengembangan kreativitas yang }
$$

dilakukan dalam proses belajar mengajar di dalam Lemabaga Akademi ini yaitu melalui proses improvisasi, yang diajarkan oleh guru pada setiap kelas agar menunjang kreativitas setiap peserta didik. Hasil dari pengembangan kreativitas melalui Lembaga Akademi Lalare Orchestra ini yaitu pada kelas biola siswa dapat memainkan alat musik biola tanpa menggunakan notasi, di dalam kelas-kelas yang lain juga demikian, siswa mampu megembangkan musik dengan kreatifitasnya masing-masing. Kreativitas mereka selama proses belajar mengajar, mereka mampu mengaransemen lagu yang sudah ada menjadi lagu yang baru, dan siswa dapat mendapatkan ilmu yang belum pernah mereka dapatkan di dalam sekolah formal. Dengan adanya pendidikan kreativitas ini mampu menjadikan Kabupaten Banyuwangi lebih maju dan terkenal lagi berkat anak-anak generasi muda yang masih mau melestarikan kebudayaan dan kesenian daerah.

\section{DAFTAR PUSTAKA}

Abramo, J. M., \& Reynolds, A. (2015). "Pedagogical Creativity" as a Framework for Music Teacher Education. Journal of Music Teacher Education, 25(1), 37-51. https://doi.org/10.1177/105708371454374 4

Astuti, R. S. (2010). Warna-Warni Kecerdasan Anak dan Pendampingannya. Yogyakarta: Kanisius.

Banoe, P. (2003). Kamus Musik. Yogyakarta: Kanisius.

Barthel, D. (1989). Historic Preservation: A Comparative Analyses. Sociological Forum, 4(1), 87-105.

Bhabha, H. K. (1994). The Location of Culture. London: Routledge.

Black, J., \& Browning, K. (2011). Creativity in Digital Art Education Teaching Practices. Art Education, 64(5), 19-34. https://doi.org/10.1080/00043125.2011.11 519140

Bryan-Wilson, J. (2017). Art+Textile Politics: Fray. Chicago: The University of Chicago Press.

Csikszentmihalyi, M. (2014). Applications of Flow in Human Development and Education. https://doi.org/10.1007/97894-017-9094-9_2

D.E, R. (2017). Pementasan Tari Gandrung 
Gandhes Sembodro Budy ${ }^{1}$, Setya Yuwana ${ }^{2}$, Setyo Yanuartuti ${ }^{3}$

Akademi Lalare Orchestra Sebagai Pengembang Kreativitas Musik Pada Anak Usia Dini di Kabupaten Banyuwangi

Dalam Tradisi Petik Laut Di Pantai Muncar, Desa Kedungrejo , Banyuwangi ,. Mudra, 32, 41-55.

Denzin, N. K., \& Lincoln, Y. S. (Eds.). (2018). The SAGE Handbook of Qualitative Research (Fifth Edit). https://doi.org/10.1007/s11229-017-1319$\mathrm{x}$

Facca, A. E., \& Aldrich, J. W. (2011). Putting the Past to Work for the Future. The Public Historian, 33(3), 38-57. https://doi.org/10.1525/tph.2011.33.3.38

Francis-Lindsay, J. (2009). The Intrinsic Value of Cultural Heritage and its Relationship to Sustainable Tourism Development: The Contrasting Experiences of Jamaica and Japan. Caribbean Quarterly, 55(2), 151168.

https://doi.org/10.1080/00086495.2009.11 829763

Ghaem Sigarchian, H., Logghe, S., Verborgh, R., de Neve, W., Salliau, F., Mannens, E., ... Schuurman, D. (2018). Hybrid eTextBooks as comprehensive interactive learning environments. Interactive Learning Environments, 26(4), 486-505. https://doi.org/10.1080/10494820.2017.13 43191

Glăveanu, V. P. (Ed.). (2016). The Palgrave Handbook of Creativity and Culture Research. United Kingdom: Palgrave Macmillan.

Habsari, S. (2005). Bimbingan dan Konseling SMA untuk Kelas XI. Jakarta: Grasindo.

Hart, D. M., Chartier, G., Kenyon, R. M., \& Long, R. T. (Eds.). (2018). Social Class and State Power: Exploring an Alternative Radical Tradition. https://doi.org/10.1007/978-3-319-648941

Holladay, P. J., \& Powell, R. B. (2018). SocialEcological Resilience and Stakeholders: A Qualitative Inquiry into CommunityBased Tourism in the Commonwealth of Dominica. Carribean Studies, 44(1), 328.

Humphreys, A. W. (1958). Creativity in music education. American Music Teacher, 8(2), 5,22 .

Iswantara, N. (2017). Kreativitas Sejarah Teori dan Perkembangan. Yogyakarta: Gigih Pustaka Mandiri.

James, K., \& Sternberg, R. J. (2010). The Cambridge Handbook of Creativity. New
York: Cambridge University Press.

Jorgensen, E. R. (2010). School music education and change. Music Educator Journal, 96(4), 21-27. https://doi.org/10.1177/002743211036977 9

Kladder, J. (2020). Re-envisioning music teacher education: An investigation into curricular change at two undergraduate music education programs in the U.S. Arts Education Policy Review, 121(4), 141159.

https://doi.org/10.1080/10632913.2019.16 70311

Koops, L. H. (2017). The Enjoyment Cycle: A Phenomenology of Musical Enjoyment of 4- to 7-Year-Olds during Musical Play. Journal of Research in Music Education, 65(3), 360-380. https://doi.org/10.1177/002242941771692 1

Lin, S.-F. (2019). Discovering Young Children's Musical Creativity in Their Everyday Life. In Y. Tsubonou, A.-G. Tan, \& M. Oie (Eds.), Creativity in Music Education (pp. 59-72). Singapore: Springer.

Lune, H., \& Berg, B. L. (2017). Qualitative Research Methods for the Social Sciences (Ninth edit). Essex: Pearson.

Mawson, W. B. (2010). Collaborative Play In Early Childhood Education. New York: Nova Science Publishing.

Miksza, P. (2013). The future of music education continuing the dialogue about curricular reform. Music Educator Journal, 99(4), 45-50. https://doi.org/10.1177/002743211347630 5

Miles, M. B., Huberman, A. M., \& Saldana, J. (2018). Qualitative Data Analysis: A Methods Sourcebook (4th ed.). New York: Sage Publications.

Partti, H., \& Karlsen, S. (2010). Reconceptualising musical learning: New media, identity and community in music education. Music Education Research, 12(4), 369-382. https://doi.org/10.1080/14613808.2010.51 9381

Sampurno, T. (2015). Seni, Melukis, dan Anak Autis: Penanganan dan Pengembangan melalui Seni dan Cara Mengevaluasi Karya Anak Autis. Yogyakarta: Psikosain. 
Scott, \& Julie-ann. (2019). Creativity, Education and the Arts Series editor. Retrieved from http://www.palgrave.com/series/14926

Silk, M., Gildenhard, I., \& Barrow, R. (2014). The Classical Tradition Art, Literature, Thought. Oxford: Wiley Blackwell.

Stevens, M. L. (2018). Culture and Education. Annals of the American Academy of Political and Social Science, 619(1), 97113. https://doi.org/10.1177/000271620832004 3

Supriadi, D. (1994). Kreativitas Kebudayaan Dan Perkembangan Iptek. Bandung: Alfabeta.

Tollefson, M. (1999). Success in every lesson. American Music Teacher, 49(2), 24-26.

Vasil, M., Weiss, L., \& Powell, B. (2019). Popular Music Pedagogies: An Approach to Teaching 21st-Century Skills. Journal of Music Teacher Education, 28(3), 8595. https://doi.org/10.1177/105708371881445 4

Warren, C. (2012). Risk and the Sacred: Environment, Media and Public Opinion in Bali. Oceania, 82(Environmental Contests; Anthropological Perspectives), 294-307. https://doi.org/10.1002/j.18344461.2012.tb00135.x

Wessing, R. (2019). A Dance of Life: The Seblang of Banyuwangi Indonesia. Bijdragen Tot de Taal-, Land- En Volkenkunde, 155(4), 644-682.

Wilcox, E. E. (2016). Beyond Internal Orientalism: Dance and Nationality Discourse in the Early People's Republic of China, 1949-1954. Journal of Asian Studies, $\quad 75(2), \quad 363-386$. https://doi.org/10.1017/S00219118150020 90

Yashi, A. P., Seblang, R., Using, M., \& Timur, B. J. (n.d.). Ritual Seblang Masyarakat Using di Banyuwangi Jawa Timur. 